\title{
General Assembly and Administrative Council Meeting of the European Federation of Internal Medicine
}

\author{
Tartu, the $27^{\text {th }}$ of September, 2014
}

The next meeting of the European Federation of Internal Medicine (EFIM) after the Congress in Geneva took place in the Senate Hall of the old University of Tartu in Estonia. The EFIM General Assembly and Administrative Council were opened by the president Maria Domenica Cappellini, and several aspects of European internal medicine were discussed. Pedro Conthe, Secretary General of the EFIM, presented a review of activities and focused on the future of European Congresses. Runolfur Palsson was elected to the post of President-elect and Antonio Martins Baptista was elected to the post of Treasurer. During the meeting a new term of Frank Bosch as the president was opened. He extended thanks to Maria Domenica Cappellini for successful presidency of the EFIM in the last years.

The position of the two journals was discussed (the European Journal of Internal Medicine and the European Journal of Case Reports in Internal Medicine) (Karena Grundy, Silvia Malosio) as well as summer and winter schools of internal medicine. The summer school took place in Costa Rei in Sardinia (Nicola Montano) and the winter school in Riga (leva Ruza). The Clinical Research Course was organized in Paris (Daniel Sereni). All these forms of activity will be continued.

The next Congress will take place in Moscow and preparations were summarized by Anatoly Martinov and Valentin Kokorin. The Congress will be organized in 2015.

Sehrat Unal presented the European project ADVICE on adult vaccination. A report on rare diseases was presented by Lorenzo Dagna, and activity of a young internist group was reviewed by Carla Aranjo.

The meeting of the Executive Board took place a day before the EFIM Administrative Council. Anna Kotuls$\mathrm{ka}$ and Eugeniusz J. Kucharz met the Executive Board and presented a request of the Polish Society of Internal Medicine to include the McMaster International Review Course in Internal Medicine in the events of the EFIM. The course was planned to take place in Krakow on June 5-6, 2015. The application was approved. The next EFIM Administrative Council will take place in Cyprus in 2015.

The Tartu meeting was organized by Margus Lember, the president of the Estonian Society of Internal Medicine, and was preceded by the Conference of the Estonian internists on multimorbidity (Photo 1). This problem affects a significant proportion of the patients hospitalized on European rheumatologic wards due to the ageing of society. The Conference entitled "Multimorbidity in internal medicine" was opened by Margus Lember and Frank Bosch. Welcome addresses were delivered by Urmas Kruuse, the Ministry of Health of Estonia, and Mari Mathiesen, the head of the national insurance fund. Lectures during the conference were delivered mostly by the members of the EFIM Executive Board. Their topics were "Multimorbidity and ageing: epidemiology of a new global epidemic" (Ramos Pujol), "Anaemia as a widespread co-morbidity in internal medicine" (Maria Domenica Cap-

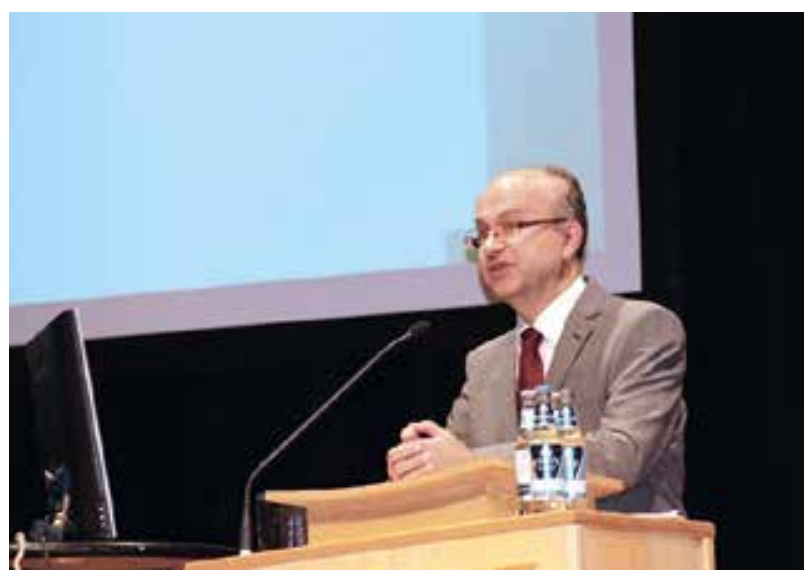

Photo 1. Tartu, September 26, 2014. Professor Magnus Lember, the president of the Estonian Society of Internal Medicine, during the opening ceremony of the conference on multimorbidity in internal medicine. 
pellini), "Impact of chronic disease on cardiovascular risk" (Pedro Conthe), "Genomics of hypertension" (Kimmo Kontula), "Adult immunization" (Serhat Unal), "Overdiagnosis and overtreatment of polymorbid internal medicine patients" (Luboš Kotik), and "Treatment limitations" (Frank Bosch). The conference took place in the new Vanremuise Concert Hall in Tartu and the EFIM meeting in the Senate Hall of Tartu University.

Tartu is a very beautiful Estonian city that has made a great contribution to the history of world medicine and sciences. It is the seat of an old university (formerly Dorpat University). The university was established on the base of the Jesuit School that was founded by the Polish king Stephen Báthory (Photo 2). The king also granted the city the Polish flag colors in appreciation of its bravery in the war with Russia. The memorial table with an inscription in Estonian and Polish was placed on the main building of the university. More than two thousand Poles have been graduates of Tartu University. The role of King Stephen Báthory is commemorated with a plate on the wall of the main building of the university.

Eugeniusz J. Kucharz



Photo 2. Tartu, September 26, 2014. The main building of Tartu University: Anna Kotulska and Eugeniusz J. Kucharz under the memorial tablet to the Polish king Stephen Báthory 